\title{
Understanding the Influencing Factors of the Effectiveness of Trusted Third Party's Trust Transformation
}

\section{Cong Cao}

School of Computing and Information Technology

University of Wollongong

New South Wales, Australia

Email: cc994@uowmail.edu.au

\section{Jun Yan}

School of Computing and Information Technology

University of Wollongong

New South Wales, Australia

Email: jyan@uow.edu.au

\section{Mengxiang $\mathrm{Li}$}

School of Business

Hong Kong Baptist University

Hong Kong SAR, China

Email: mengxiangli@hkbu.edu.hk

\section{Abstract}

Through the experimental data analysis, this paper found that trusted third parties (TTPs) can effectively reduce the trust barrier of consumers. Furthermore, we point out that TTPs have the function of trust transfer, which provides a meaningful framework for our understanding of the mechanism of TTPs. According to this research, consumers' trust in unfamiliar enterprises is built on their trust of TTPs. The chain relationship of TTPs' trust and certification of enterprises and consumers' recognition of TTPs enables the transfer of consumer trust to enterprises and finally leads to consumers' trust in these enterprises. Also, the reputation and presentation of TTPs can have a significant influence on the trust transfer. The results further reveal the internal mechanism of TTPs and clarify the regulatory factors that influence the trust transfer. These findings are helpful for understanding and extension of relevant theories and enterprises' decision making on TTPs.

Keywords online shopping, trusted third party, trust formation, trust transformation, reputation, presentation type. 


\section{Introduction}

Electronic commerce (e-commerce) continues to maintain a high pace of development. In 2015, the ecommerce market accumulated a staggering $\$ 1.672$ trillion, which accounted for $7.3 \%$ of total global retail sales of \$22.822 trillion (Chung 2015). According to National Australia Bank Limited statistics released in 2017, the online shopping amount of Australian reaches $\$ 21.65$ billion across both physical goods and digital services in 2016 (National Australia Bank Limited 2017). This is a total increase spend of 10.4\% compared to 2015 (National Australia Bank Limited 2017). However, behind the prosperity, the development of e-commerce is also confronted with some challenges. An important issue is how to build trust between the parties involved in the online transaction (Corbitt et al. 2003). In fact, whatever stage the e-commerce has developed to, the building, maintaining and enhancing of online trust are always an issue of primary importance (Kim et al. 2008). The Australian Competition and Consumer Commission (ACCC) receives around 105,000 scam complaints in 2015, which is 14,000 more than that in 2014. The reported lost money increases by $4 \%$ and totals $\$ 85$ million (Australian Competition and Consumer Commission 2015). In the same period, the Australian Cybercrime Online Reporting Network (ACORN) reveals reported losses of over $\$ 127$ million due to e-commerce scams and lack of trust on the virtual market (Australian Competition and Consumer Commission 2015). The results of research reported by Hong-ling and Guang-xing (2011) indicate that the trust is one of the important promoting factors of achieving success in e-commerce. The problems in the early stage of development of ecommerce have been gradually solved when related technologies are advancing, and the infrastructure is perfected, such as online payment, information security, logistics and distribution, policy and laws (Hsu 2008). Currently, in order to further expand e-commerce, how to build up and maintain the level of trust between the transaction counterparties become a very important issue to be solved (Cheung and Lee 2006).

Researchers and practitioners in the field of e-commerce attempt to build and promote online trust by different means. Enhancing the trustworthiness with Trusted Third Parties (TTPs) has become a strategy widely adopted by enterprises. Researchers have carried out profound studies of the influence of TTPs on consumer trust, but no consensus has been achieved in respect of the influence of TTPs on the trust intention. For example, some studies argue that TTPs can significantly improve consumer trust in enterprises (Head and Hassanein 2002; Hu et al. 2010; Kim et al. 2008), but other studies point out that no significant influence can be found. Therefore, in our opinion, more in-depth research must be undertaken (McKnight et al. 2004; Moores 2005; Moores and Dhillon 2003).

On the other hand, although it is expected to build trust in a relatively unknown Internet environment by using services offered by TTP, the TTP-based online trust mechanism and its relative effectiveness are still not sufficiently understood. The online trust building in an Internet environment can be well comprehended only after knowing the specific role of TTP in the process of trust building and transfer, as well as the effectiveness of TTP on consumer trusting behaviours. This may also provide an effective practical guide for online trust strategies. Therefore, the objective of this research is:

\section{To investigate the influencing factors of the effectiveness of TTP trust transfer.}

The questionnaire-based empirical research is usually used by previous studies to explore the influence of TTPs on consumers' behaviours (Cook and Luo 2003; McKnight et al. 2004; Özpolat and Jank 2015). But it is difficult to make an accurate judgement about the causal relationship between the independent variable (TTPs) and the dependent variable (trust intention) due to the widespread existence of extraneous variables. For these reasons, we decided to examine the influence of TTPs on consumers' trust intention through laboratory testing in a controlled environment.

This paper investigates the mechanism of TTPs in the online shopping environment and points out that they have an important function of enabling the trust transfer during online consumers' trust formation. Further, we examine the influence and regulatory roles of TTPs' different types of reputation and forms of presentation on the trust transfer. A laboratory experiment is performed with $2 \times 2$ treatment groups to validate the research model and hypotheses proposed herein. The experimental data analysis with the Partial Least Squares Structural Equation Modeling (PLS-SEM) and Partial Least Squares Multi-Group Analysis (PLS-MGA) shows that TTPs can influence consumers' trust intention and behaviours by their trust transfer function. The reputation of TTPs has a positive influence on trust transfer. In addition, it is also found that the detailed and specific TTP description and presentation can significantly enhance consumers' trust expectations and reduce their risk perception. The results not only enrich relevant theories of TTPs, but also provide some reliable guidance for enterprises in using and selecting TTPs.

The remaining sections of this paper are organised as follows. In the second section, we conduct a literature review of online trust and TTPs. The third section gives an introduction to the theoretical basis 
and research hypothesis of this research. In the fourth section, the research methodology is explained in detail. The fifth section presents the analysis results of the experimental data. In the sixth section, the research findings and significance have been made clear, and the limitations and suggestions for further research are pointed out. The last section provides an overview of the major findings and arrives at conclusions.

\section{Literature Review}

The e-commerce has attracted increasingly more attention from merchants and consumers because of the advantages of the internet being highly interactive and convenient. Meanwhile, online trust plays a critical role in the online transaction environment due to the virtual nature and time-space separation (Cao and Yan 2014). According to existing studies, online trust is widely accepted as one of the key factors that can influence and promote online transactions (Gefen et al. 2003; Guan and Lala 2017). Therefore, it is important to analyse the main factors for the formation of online trust and study the online trust building mechanism during the development of e-commerce.

Researchers indicate that online trust can play the roles of increasing the predictability of behavioural outcomes, decreasing transaction costs, lessening opportunistic behaviours and reducing uncertainties in partners, thus making the transaction relations more foreseeable and meeting needs (Fam et al. 2004; Fang et al. 2014; Head and Hassanein 2002). From the above research results, it can be observed that if enterprises can prove to consumers that online shopping is trustworthy, this will reduce their risk perception and finally be helpful for the development of online transactions (Hong-ling and Guang-xing 2011; Lim et al. 2006).

A lot of researchers have made insightful studies of consumers' initial trust-building mechanism and formation factors of online trust. The results of the empirical studies show that consumers' perceived usefulness, ease of use and security of web pages are important preconditions for the formation of trust (Sia et al. 2009). Further studies indicate that the reputation of enterprises, consumers' trust intention and structural assurance (namely institution-based trust) have a significant influence on consumers' trust intention (Guo and Jaafar 2011; Hoffman et al. 1999; Kim et al. 2008).

In the industry, a large number of TTPs appear to solve the issue of consumer trust in online transactions. These TTPs provide support for the success of online transactions by different technical means and offering intermediary services. For example, VeriSign secures consumers' online transactions, and TRUSTe provides privacy seal to demonstrate enterprises' compliance with their commitment to privacy protection, thus effectively easing users' concern about their privacy.

In recent years, the research of TTPs has aroused the widespread attention of researchers. Relevant research points out that TTP, as a control mechanism for online transactions, can restrict opportunistic behaviour, effectively eliminate consumers' distrust, increase the number of potential transactions in the future and help to build up a long-term trust relationship between both parties (Benassi 1999; Kimery and McCord 2002). These articles provide valuable contributions to our understanding of the significance and functions of TTPs. However, there are also different voices. For example, based on data collected from questionnaires, some studies argue that TTPs have no significant influence on consumers' trust intention (Cook and Luo 2003; McKnight et al. 2004; Moores 2005; Moores and Dhillon 2003).

As stated above, in our opinion, it is necessary to study the real influence of TTPs on the trust intention by laboratory experiments with the control of extraneous variables. Moreover, the existing research often expounds the influence of TTPs on consumers' behaviours, but seldom explains the mechanism and influencing factors. Therefore, we create $2 \times 2$ treatment groups for an in-depth discussion of the functions of TTPs and the corresponding regulatory factors, so as to achieve an insightful understanding of TTP.

\section{Theoretical Background and Hypotheses}

Due to some characteristics of online shopping, such as separation of transaction counterparties in space, asynchronous payment and delivery in time, and use and disclosure of personal information (such as name, address, credit card information etc.), online transactions face greater risks compared with the traditional transaction mode (Head and Hassanein 2002). On the other hand, because consumers are unlikely to have all the information about the products and enterprises, they possibly make wrong decisions and even give up transactions (Hong-ling and Guang-xing 2011). At this point, if enterprises accurately transfer the signals containing their own advantages to consumers (e.g. higher quality signage, description of more reasonable prices, easier return policy, trustworthy credentials and third-party 
certifications), this can lessen consumers' cost of information collection, reduce their risk perception, promote the formation of trust and increase the quantity of finalized transactions (Fang et al. 2014; Head and Hassanein 2002).

In order to effectively solve the problems above, there emerges a lot of TTPs on the e-commerce market to act as a credit intermediary, whose economic function is to provide the trustworthiness of other enterprises by their trustworthiness formed in the long-term business operation, especially newly incorporated unknown enterprises. This aims to reduce the asymmetry of information on the ecommerce market and reduce consumers' transaction costs, thus promoting their online sales.

Therefore, TTPs have the information transfer function that can facilitate the flow of trustworthy information among online transaction parties and enable consumers to have a more reliable understanding of the trustworthiness of enterprises before transactions. By such function of TTPs, it is easier for both parties of an online transaction to establish a trust relationship.

In the presence of TTPs, the trustworthy information of both parties of the transaction flows between consumers and enterprises through TTPs and finally results in the transfer of both parties' trustworthy information. Consumer trust in unfamiliar enterprises is built on their trust of TTPs. Due to TTPs' certification of enterprises and consumers' trust of TTPs, this kind of chain relationship transfers consumer trust to enterprises and finally leads to their trust in enterprises.

To test the trust transfer function of TTPs in a laboratory environment, we construct the research framework for this research based on the Theory of Planned Behavior (TPB) and the online trust model, as presented in Figure 1.

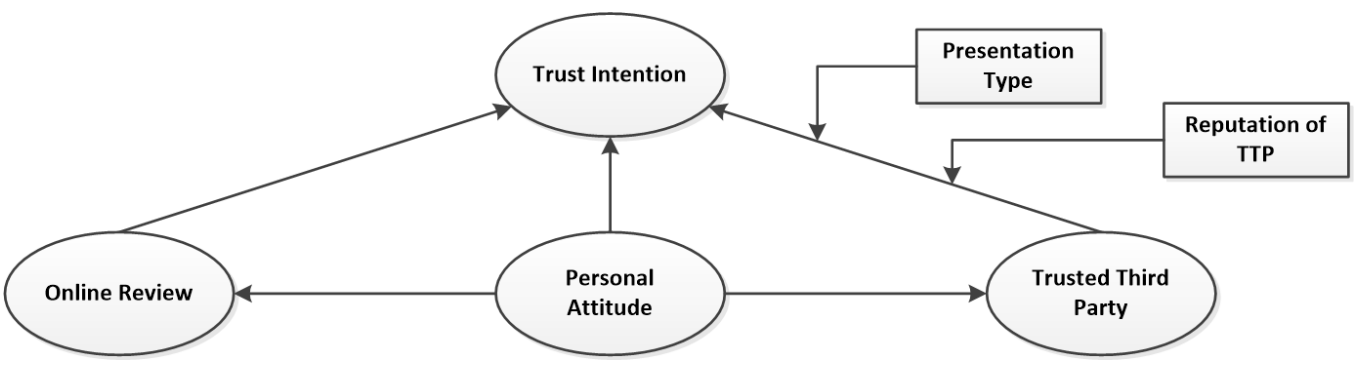

Figure 1: Research Framework

In our opinion, consumers' behaviours are generally in line with the explanation of TPB, that is, the behavioural decision is controlled by their own will and rational. When they have time to think over their behaviours, the behavioural intention is the best way to examine their behaviours. To be specific, with regards to the development of trust behaviour and buying decision in the online shopping environment, consumers are often restricted by time, money, information and personal ability, so their behavioural intention is influenced by other factors. As further pointed out by Cao and Yan (2014)'s research, consumers' personal attitude, online reviews and TTP are three main influencing factors of behavioural intention in the online environment. Taking online trust as an example, if consumers' trust attitude and online reviews are more positive and TTPs provide stronger support, consumers have more trust intention, vice versa.

Based on the above theories, we mainly divide the influencing factors of consumers' trust intention into personal attitude, online reviews and TTPs. The trust intention is the dependent variable and TTP is the independent variable of this experiment. Other influencing factors of the trust intention, such as online reviews and consumers' personal attitude, are extraneous variables under strict control in this laboratory experiment. By control of extraneous variables, their influence on the experimental results are limited, and a relatively high internal validity is obtained, thus laying a solid basis for explaining the causal relationship between TTP and trust intention.

In an e-commerce environment lack of trust, a reliable TTP can play an enormous role. In a virtual environment, consumers often transact with a particular enterprise for the first time, so they expect extra reliable third-party protection. According to Head and Hassanein (2002), the trust of TTPs can effectively enhance consumer trust. Guan and Lala (2017) further point out that the trusted third party has the most important influence on consumer trust. Kimery and McCord (2002)'s research also proves that TTP has a significant influence on consumer trust. Hence, the following hypothesis is put forward:

H1. Consumer-perceived TTP has a positive influence on consumers' trust intention. 
To further explore the mechanism and influencing factors of TTPs, we first examine a variety of TTPs on the market. It is found that in addition to some TTPs with very high popularity and reputation, there are also some emerging TTPs on the market. Judging from the reputation and popularity, there are two types of TTPs, namely, high reputation and low reputation. Of course, these companies often adopt different strategies in pricing and charging modes. According to the explanation of the Signaling Theory, enterprises transfer their trustworthy signals to consumers through TTPs, thereby influencing consumers' trust intention. Accordingly, we believe that TTPs with higher reputation can transfer stronger signals and have a more significant influence on consumers. Therefore, we propose the following hypothesis:

H2. The reputation of TTP shows the moderation effect on the relationship between TTPs and trust intent.

Through the exploration of the TTPs used by enterprises and their form of presentation on web pages, the research indicates that TTPs are mainly presented in two forms: abstract logo and concrete description. For example, some enterprises display the certification logo issued by TTPs to support their eligibility. This form of presentation is mainly used to show various types of security certifications, payment certifications and privacy certifications. By displaying TTP's logo visibly on the webpage, they achieve the influence of consumers' trust intention. Another form of presentation uses concrete description to explain the corresponding certifications obtained by the enterprise. For example, a description is provided to the service type and the start and end times of the service certification. Enterprises try to explain the role of TTP services to consumers through detailed descriptions and further influence consumers' behavioural intention. By concrete information disclosure and service description, enterprises can effectively reinforce the trustworthy signals perceived by consumers, reduce the risk expectation and enhance their trust in enterprises. Therefore, this paper believes that:

H3. The form of presentation of TTP shows the moderation effect on the relationship between TTPS and trust intent.

\section{Research Methodology}

\subsection{Experimental Design}

In order to explore the trust transfer mechanism and influencing factors of TTPs, we create $2 \times 2$ treatment groups according to the reputation (high or low reputation) and form of presentation (abstract and concrete) to test the research hypotheses. We design an online shopping webpage with a professional appearance to simulate the real online shopping environment. We have carefully chosen products to be sold on the webpage, primarily digital products such as smartphones, cameras and acoustics. Further, the introduction, description, reviews, replacement and return policy and company profile of these products are designed and displayed to resemble real e-commerce websites. For the experiment, we have used four versions of web pages and displayed TTP services at easily visible places.

To minimise the interference of extraneous variables on the experimental results, we mainly take the following measures during the experiment:

First, as revealed by the related study, the design, style, function and features of the webpage can have a certain degree of influence on consumer attitude (Ganguly et al. 2009; Ganguly et al. 2010). To avoid the interference of these factors, a well-known online seller (JB Hi-Fi Group Pty Ltd) is selected as the reference case for this experiment. The webpage used in the experiment is designed based on the JB HiFi's webpage (https://www.jbhifi.com.au). Then, 15 volunteers are recruited to test and validate the webpage used in the experiment, for ensuring that the experimental environment can simulate the real online shopping scenarios.

Second, as Cao and Yan (2014) explained in their trust model, consumers' trusting intention is influenced not only by TTPs, but also by reviews of other consumers, consumers-perceived reputation and their propensity to trust. All these factors are likely to interfere with the results observed in the experiment in the form of extraneous variables. To further control the influence of these factors on consumer behaviours, based on the online trust model proposed by Cao and Yan (2014), this research divides extraneous variables into the following two types: consumer attitude and reviews perceived by consumers. The possible influence of consumer attitude on the experiment is effectively controlled through the qualification review of participants. By presenting the neutral consumer reviews, the potential influence of online reviews on participants can be further controlled in the experimental simulation environment. 
With the above-mentioned design control approach of the experiment, the control is established for specific extraneous variables (e.g. personal attitude, level of disposition to trust, webpage and reviews) that can influence consumers' behavioural intentions and the variables to be tested in this experiment (presentation and reputation) are operated to obtain a high internal validity and reduce the influence and interference of extraneous variables on the experimental results.

\subsection{Participants}

The participants in this experiment are college students, who voluntarily participate without receiving any compensation and are randomly distributed to four different treatment groups. Table 1 shows the demographic characteristics. $54 \%$ of participants are male, and the most of them (89\%) fall into the age group from 18 to 35 . More than half of participants shop online for over 12 times and have a very high level of internet skills (mean $=5.84$, S.D. $=1.03$, on a 7-point Likert scale with $1=$ lowest and $7=$ highest).

\begin{tabular}{llll}
\hline Measure & Category & $\mathrm{N}$ & Per cent \\
\hline \multirow{2}{*}{ Gender } & Male & 54 & $54.00 \%$ \\
& Female & 46 & $46.00 \%$ \\
Age & $18-24$ & 47 & $47.00 \%$ \\
& $25-34$ & 42 & $42.00 \%$ \\
Education & Undergraduate & 61 & $11.00 \%$ \\
& Postgraduate & 17 & $22.00 \%$ \\
Shopping & O-6 & 7 & $61.00 \%$ \\
Frequency & $7-11$ & 32 & $17.00 \%$ \\
(per year) & $>12$ & 61 & $7.00 \%$ \\
\hline
\end{tabular}

Table 1. The Demographic Profile of Respondents $(N=100)$

\subsection{Procedures}

Before the experiment formally starts, participants are required to enter the computer laboratory, sit down and open the description file stored in computers. Then a brief description is given to the purpose and procedure of the experiment in 5 minutes and guides participants to read the description file stored in computers. Then participants in different treatment groups are instructed to open different versions of web pages and browse them carefully in 15 minutes. Next, a piece of the questionnaire is filled by each participant in 10 minutes so as to collect their demographic characteristics and data about trust intention and behaviours for further analysis. Finally, gratitude is expressed to all participants in this experiment. The experiment has been performed for four times lasting 30 to 35 minutes each. One treatment group has 25 participants, and a total of 100 pieces of data are collected.

\subsection{Data Analysis}

The PLS-SEM has good explanatory power in the case of a small sample size, but without requiring the normal distribution of data, so this approach is utilised for testing the research model and hypotheses proposed herein. First of all, the measurement model is assessed to test the reliability and validity of different constructs. Then, through the assessment of the structural model, we examine the relations of different constructs and the model predictability. Finally, the PLS-MGA is applied for exploring the regulatory role of other relevant factors on the trust transfer.

\section{Results}

\subsection{Measurement Model}

In this research, the Composite Reliability (CR) and Cronbach's a (CA) are used to test the internal consistency reliability, and the outer loadings are used to test the indicator reliability. In Table 2, the $\mathrm{CR}$ and CA values of all latent variables are larger than 0.7 , and the outer loadings of the constructs of all measurement indicators are larger than 0.708. All these facts indicate that the measurement model of this research has very good reliability (Hair et al. 2012). 


\begin{tabular}{lllll}
\hline Constructs & Items & CA & CR & AVE \\
\hline Trust Intention (TI) & 5 & 0.864 & 0.902 & 0.648 \\
Online Review (OR) & 3 & 0.910 & 0.944 & 0.848 \\
Personal Attitude (PA) & 5 & 0.930 & 0.947 & 0.781 \\
Trusted Third Party (TTP) & 4 & 0.912 & 0.938 & 0.792 \\
\hline
\end{tabular}

Table 2. The Descriptive Statistics for the Constructs

The average variances extracted (AVE) is used for assessing the convergent validity of the measurement model, and the Fornell-Larcker criterion and the cross-loadings for assessing the discriminant validity. As shown in Table 2, the AVE values of all constructs are larger than 0.5, indicating good convergent validity (Barclay et al. 1995). The outer loadings of constructs of any indicators in Table 3 are larger than the cross-loadings between them and other constructs. Also, as shown in Table 4, the AVE of any construct in the model is larger than corresponding correlation values with other constructs. All these facts indicate that the measurement model has sufficient discriminant validity (Hair et al. 2012).

\begin{tabular}{lllll}
\hline & TI & OR & PA & TTP \\
\hline TI.1 & $\mathbf{0 . 8 0 5}$ & -0.178 & -0.221 & 0.139 \\
TI.2 & $\mathbf{0 . 8 4 6}$ & -0.117 & -0.204 & 0.146 \\
TI.3 & $\mathbf{0 . 7 4 5}$ & -0.115 & -0.096 & 0.001 \\
TI.4 & $\mathbf{0 . 7 7 6}$ & -0.157 & -0.193 & 0.21 \\
TI.5 & $\mathbf{0 . 8 4 7}$ & -0.123 & -0.235 & 0.16 \\
OR.1 & -0.179 & $\mathbf{0 . 8 6 9}$ & -0.33 & 0.011 \\
OR.2 & -0.178 & $\mathbf{0 . 8 5 7}$ & -0.236 & -0.055 \\
OR.3 & -0.111 & $\mathbf{0 . 9 0 2}$ & -0.321 & -0.011 \\
PA.1 & -0.256 & -0.370 & $\mathbf{0 . 9 1 9}$ & -0.543 \\
PA.2 & -0.165 & -0.284 & $\mathbf{0 . 8 7 4}$ & -0.545 \\
PA.3 & -0.178 & -0.253 & $\mathbf{0 . 8 6 0}$ & -0.523 \\
PA.4 & -0.203 & -0.295 & $\mathbf{0 . 8 6 1}$ & -0.545 \\
PA.5 & -0.258 & -0.297 & $\mathbf{0 . 9 0 4}$ & -0.571 \\
TTP.1 & 0.181 & -0.031 & -0.569 & $\mathbf{0 . 9 0 8}$ \\
TTP.2 & 0.141 & -0.006 & -0.564 & $\mathbf{0 . 8 9 6}$ \\
TTP.3 & 0.083 & -0.042 & -0.488 & $\mathbf{0 . 8 5 2}$ \\
TTP.4 & 0.179 & 0.004 & -0.568 & $\mathbf{0 . 9 0 2}$ \\
\hline
\end{tabular}

Notes: Bold number indicate item loading on the assigned constructs.

Table 3. The Factor Loadings and Cross Loadings

\begin{tabular}{lllll}
\hline & TI & OR & PA & TTP \\
\hline TI & 0.805 & & & \\
OR & -0.171 & 0.876 & & \\
PA & -0.207 & 0.033 & 0.899 & \\
TTP & 0.32 & 0.218 & -0.611 & 0.909 \\
\hline
\end{tabular}

Notes: Boldface values on the diagonal are the square root of the AVE.

Table 4. The Correlation Between the Dimensions 


\subsection{Structural Model}

By bootstrapping in the Smart PLS, the t-test of significance is conducted for the path coefficient. The original number of samples is 100 , and the maximum number of iterations is 5000 . The path coefficient and the significance test results are shown in Figure 2. The results of the empirical research show that consumers' perception of TTP services can significantly influence their trust intention of online shopping.

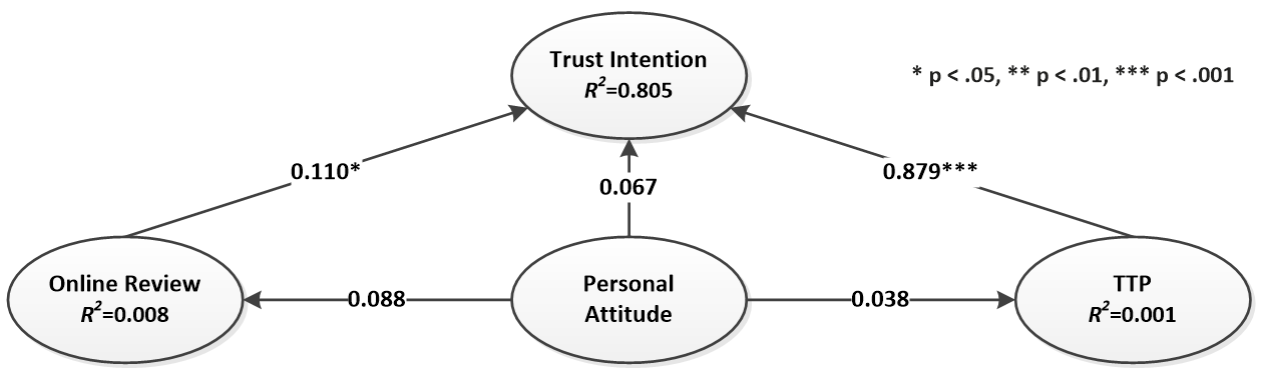

Figure 2: PLS-SEM Analysis Results

The coefficient of determination $\left(\mathrm{R}^{2}\right)$ reflects the degree of explanation of extraneous latent variable to endogenous latent variable. If $\mathrm{R}^{2}>0.67$, the latent variable has strong explanatory power, $\mathrm{R}^{2}=0.33$ denotes moderate explanatory power, and $\mathrm{R}^{2}=0.19$ means weak explanatory power (Hair et al. 2012). The value of $\mathrm{R}^{2}$ is 0.805 for consumers' trust intention in the model hereof and reaches a high level. This indicates that the model proposed herein has good explanatory power.

\subsection{Multi-group Analysis}

In order to understand the influence of TTP reputation and form of presentation on the trust transfer in the online shopping environment, in this research, the parametric approach to PLS-MGA proposed by Sarstedt et al. (2011) has been used for testing the existence of heterogeneity. Through the f PLS-MGA and the independent samples t-test, the results show that they play a regulatory role to the trust transfer. The data are presented in Table 5 and Table 6.

\begin{tabular}{llll}
\hline Path & Path Coefficients Difference & t-Value & p-Value \\
\hline PA->OR & 0.012 & 0.054 & 0.957 \\
PA->TTP & 0.167 & 1.539 & 0.125 \\
OR->TI & 0.316 & 1.273 & 0.204 \\
PA->TI & 0.226 & 1.436 & 0.152 \\
TTP->TI & $\mathbf{0 . 8 0 5}$ & $\mathbf{3 . 3 8 1}^{* * *}$ & $\mathbf{0 . 0 0 1}$ \\
\hline
\end{tabular}

Table 5. The Parametric Significance Test - High Reputation vs Low Reputation

\begin{tabular}{llll}
\hline Path & Path Coefficients Difference & t-Value & p-Value \\
\hline PA->OR & 0.028 & 0.128 & 0.898 \\
PA->TTP & 0.063 & 0.585 & 0.559 \\
OR->TI & 0.269 & 1.066 & 0.287 \\
PA->TI & 0.194 & 1.374 & 0.17 \\
TTP-> TI & $\mathbf{0 . 4 1 4}$ & $\mathbf{1 . 9 6 2}^{*}$ & $\mathbf{0 . 0 5}$ \\
\hline
\end{tabular}

Table 6. The Parametric Significance Test - Abstract Presentation vs Concrete Presentation

\section{Discussion and Implications}

\subsection{Summary of Results}

The enterprises' credit information cannot be effectively transferred to consumers due to obstruction and no circulation of information in the online shopping environment, thus causing their distrust of 
enterprises (Kim et al. 2008). Being unable to access effective information, consumers are often very cautious in the process of online transactions and lack of trust in merchants. This further results in their reject of potential transactions even in the face of trustworthy enterprises (Guo and Jaafar 2011).

The emergence of TTPs has effectively eased the problems above, reduced the information asymmetry, decreased the cost of searching for information by consumers, facilitated the establishment of a trust relationship and further promoted the development of e-commerce (Özpolat and Jank 2015). Through the analysis of experimental data, this study first provides the reliable evidence that TTPs have a significant influence on consumers' trust intention. In other words, TTPs are favourable for consumers' understanding of enterprises' trustworthy information and effectively promote the level of trust between consumers and enterprises, thus possibly increasing the potential transaction volume.

Further, this research explains the trust transfer function of TTPs in the e-commerce environment and how TTPs transfers consumers' trust in them to target enterprises. In the process of trust transfer, the reputation and presentation of TTPs will play an important regulatory role. Specifically, the higher the reputation of TTP, the higher consumers' recognition, and further the degree of consumer trust in enterprises will be significantly enhanced. On the other hand, the concrete presentation is easier to receive consumers' recognition of TTPs than the abstract presentation, and thus significantly promoting their trust in enterprises.

In our opinion, the influence of TTPs on consumers' behavioural intention is realised by means of trust transfer. Therefore, the degree of consumer trust in TTPs and the effectiveness of trust transfer can significantly influence the level of trust between consumers and enterprises.

There are primarily three parties involved in the online transaction, including consumers, TTPs and enterprises. TTPs build up very good trustworthiness in their long-term market operations. Enterprises transfer their trustworthy information to consumers through TTP services for reducing risks perceived by consumers and enhances their trust in enterprises. Two key points exist in this process of trust transfer, namely consumers' trust in TTP and TTP's certification of enterprises. The former determines the degree of trust transfer, and the latter determines the effect of trust transfer. That is to say, the higher the reputation TTPs have, the more trust consumers will have in them. According to our research, consumers are more willing to accept and recognise the guarantee and certification provided by highreputation TTPs for other enterprises. Moreover, when enterprises present the TTP guarantee and certification, the concrete and detailed description can more easily influence consumers' perception of trust. In summary, the trust transfer mechanism of TTP is influenced by its reputation and form of presentation, both of which have a significant regulatory effect on consumers' trust intention.

\subsection{Theoretical and Industrial Significance}

With the prosperous development of online shopping, research interests on TTP are increasing with gradually enriched achievements. On the whole, this research also makes some contribution to this field. First of all, we elaborate on the trust transfer function of TTP and explain how the TTP certification service transfers trust to unfamiliar online enterprises. These have enriched related literature in the field of TTP. Secondly, we also have an in-depth discussion of the internal mechanism of TTPs and point out the reputation and form of presentation are the two important factors that can influence and regulate the trust transfer. These results further enrich related theories and extend our understanding of TTPs. Finally, the laboratory environment constructed in this research provides a very high degree of control and thereby resulting in a relatively high level of internal validity. This creates a favourable condition for us to explore and investigate the influence of TTPs on consumers' behaviours.

As regards enterprises, our research provides valuable guidance for their decision on TTP use. TTPs positively influence consumers' trust intention, so enterprises should try their best to adopt the services provided by TTPs, for effectively enhancing consumers' trust level and promote potential transaction volume.

How to choose among all kinds of TTPs on the market is a challenge for enterprises. Our research results show that TTPs with higher reputation have a more significant influence on consumers' trust intention. Accordingly, enterprises should cooperate with TTPs with high reputation on the market, such as TRUSTe, VeriSign and BBBOnLine, because they can more effectively transfer the trustworthy information to potential customers, strengthen their trust in enterprises and influence future transactions.

Moreover, our research provides valuable insight for TTPs and their users. Our experimental results indicate that concrete presentation, that is, the detailed description and promotion of the service and certification provided by TTP can effectively enhance the degree of consumer trust in enterprises. 
Accordingly, enterprises should not just display simple and abstract icons when presenting TTPs, but give a detailed description of the services and requirements provided by the TTPs and show their trustworthy information to consumers, so as to reduce consumers' perception of risks and create a friendly online shopping environment.

\subsection{Limitations and Future Research}

Although this research has carried out a beneficial exploration of the trust transfer mechanism of TTPs in the online shopping environment, there are still limitations. First, 100 samples satisfy the requirement of minimum sample size by the PLS, but more samples can effectively improve the model predictability and accuracy. Next, the age and education of participants are confined only to college students, so the experimental results cannot be simply extended to consumers made up of different groups in the real online shopping environment. In our future research, it is necessary to more widely collect data of different consumer groups for more reasonably explain the experimental results. Finally, due to the characteristics of a laboratory experiment, there may be demand artifact among participants, and the external validity is also lower than the field experiment. Therefore, the applicability of these experimental results to the real world is possibly weak. In future research, the field experiment may be conducted, for example, real buying behaviours of consumers on online shopping websites with TTPs.

\section{Conclusion}

Due to the virtual nature, anonymity and separation of time and space in the online shopping environment, online trust plays an indispensable role (Fam et al. 2004). Past empirical studies have pointed out that the various services provided by TTPs can effectively alleviate uncertainties consumers face in shopping and enhance their sense of trust, thus improving online transactions of enterprises and promote the development of e-commerce (Hu et al. 2010; Kimery and McCord 2002). Although related research reports that TTPs can significantly influence consumers' trust intention and shopping behaviour decision-making, existing research is seldom carried out by means of laboratory experiments, nor explores the internal mechanism of TTPs. Based on experimental data, this research not only enterprises the significant influence of TTPs on consumers' behaviour, but further explains their trust transfer function in the online shopping environment. Moreover, it also reveals regulatory factors of the trust transfer, namely the reputation and form of presentation of TTPs. Our research results show that the certification service of enterprises provided by TTPs with high reputation can significantly improve the degree of consumer trust in enterprises. The concrete and detailed description and presentation of TTP services can effectively enhance consumers' cognition of TTP services and therefore influence their behavioural intention. In general, the explanation of the trust transfer function and influencing factors of TTPs in this research not only fills the gap of TTP research, but also provides useful guidance for enterprises in choosing TTP services. Of course, we also make clear the limitations and the direction for future research.

\section{Acknowledgements}

The research described in this paper was supported by a grant from the State Scholarship Fund by China Scholarship Council (File No. 201308200014) and a grant from the International Postgraduate Tuition Award by the University of Wollongong, Australia.

\section{References}

Australian Competition and Consumer Commission. 2015. "Targeting Scams: Report of the Accc on Scam Activity 2015."

Barclay, D., Higgins, C., and Thompson, R. 1995. The Partial Least Squares (Pls) Approach to Casual Modeling: Personal Computer Adoption and Use as an Illustration.

Benassi, P. 1999. "Truste: An Online Privacy Seal Program," Communications of the ACM (42:2), pp. 56-59.

Cao, C., and Yan, J. 2014. "Towards a Trust Model for Trust Establishment and Management in Business-to-Consumer E-Commerce," IEEE 11th International Conference on Autonomic and Trusted Computing pp. 479-486.

Cheung, C. M., and Lee, M. K. 2006. "Understanding Consumer Trust in Internet Shopping: A Multidisciplinary Approach," Journal of the American society for Information Science and Technology (57:4), pp. 479-492.

Chung, H.-S. 2015. "Online Adr for the E-Commerce: European Union's Adr Legislation for CrossBorder Online Trade," J. Arb. Stud. (25), p. 135. 
Cook, D. P., and Luo, W. 2003. "The Role of Third-Party Seals in Building Trust Online," e-Service Journal (2:3), pp. 71-84.

Corbitt, B. J., Thanasankit, T., and Yi, H. 2003. "Trust and E-Commerce: A Study of Consumer Perceptions," Electronic commerce research and applications (2:3), pp. 203-215.

Fam, K. S., Foscht, T., and Collins, R. D. 2004. "Trust and the Online Relationship-an Exploratory Study from New Zealand," Tourism Management (25:2), pp. 195-207.

Fang, Y., Qureshi, I., Sun, H., McCole, P., Ramsey, E., and Lim, K. H. 2014. "Trust, Satisfaction, and Online Repurchase Intention: The Moderating Role of Perceived Effectiveness of E-Commerce Institutional Mechanisms," Mis Quarterly (38:2).

Ganguly, B., Dash, S. B., and Cyr, D. 2009. "Website Characteristics, Trust and Purchase Intention in Online Stores:-an Empirical Study in the Indian Context," Journal of Information Science \& Technology (6:2).

Ganguly, B., Dash, S. B., Cyr, D., and Head, M. 2010. "The Effects of Website Design on Purchase Intention in Online Shopping: The Mediating Role of Trust and the Moderating Role of Culture," International Journal of Electronic Business (8:4-5), pp. 302-330.

Gefen, D., Karahanna, E., and Straub, D. W. 2003. "Trust and Tam in Online Shopping: An Integrated Model," MIS quarterly (27:1), pp. 51-90.

Guan, L., and Lala, V. 2017. "Role of Trust and Involvement in the Effectiveness of Digital Third-Party Organization Endorsement," Atlantic Marketing Journal (6:1), p. 5.

Guo, J., and Jaafar, N. I. 2011. "A Study on Consumers' Attitude Towards Online Shopping in China," International Journal of Business and Social Science (2:22).

Hair, J. F., Sarstedt, M., Ringle, C. M., and Mena, J. A. 2012. "An Assessment of the Use of Partial Least Squares Structural Equation Modeling in Marketing Research," Journal of the academy of marketing science (40:3), pp. 414-433.

Head, M. M., and Hassanein, K. 2002. "Trust in E-Commerce: Evaluating the Impact of Third-Party Seals," Quarterly Journal of Electronic Commerce (3), pp. 307-326.

Hoffman, D. L., Novak, T. P., and Peralta, M. 1999. "Building Consumer Trust Online," Communications of the ACM (42:4), pp. 80-85.

Hong-ling, M., and Guang-xing, S. 2011. "An Overview of Trust Mechanism and Applications of ECommerce," Management and Service Science (MASS), 2011 International Conference on, pp. 1-5.

Hsu, C.-J. 2008. "Dominant Factors for Online Trust," Cyberworlds, 2008 International Conference on: IEEE, pp. 165-172.

Hu, X., Wu, G., Wu, Y., and Zhang, H. 2010. "The Effects of Web Assurance Seals on Consumers' Initial Trust in an Online Vendor: A Functional Perspective," Decision Support Systems (48:2), pp. 407-418.

Kim, D. J., Ferrin, D. L., and Rao, H. R. 2008. "A Trust-Based Consumer Decision-Making Model in Electronic Commerce: The Role of Trust, Perceived Risk, and Their Antecedents," Decision Support Systems (44:2), pp. 544-564.

Kimery, K. M., and McCord, M. 2002. "Third-Party Assurances: The Road to Trust in Online Retailing," System Sciences, 2002. HICSS. Proceedings of the 35th Annual Hawaii International Conference on, p. $10 \mathrm{pp}$.

Lim, K. H., Sia, C. L., Lee, M. K., and Benbasat, I. 2006. "Do I Trust You Online, and If So, Will I Buy? An Empirical Study of Two Trust-Building Strategies," Journal of management information systems (23:2), pp. 233-266.

McKnight, D. H., Kacmar, C. J., and Choudhury, V. 2004. "Shifting Factors and the Ineffectiveness of Third Party Assurance Seals: A Two - Stage Model of Initial Trust in a Web Business," Electronic Markets (14:3), pp. 252-266.

Moores, T. 2005. "Do Consumers Understand the Role of Privacy Seals in E-Commerce?," Commun. $A C M(48: 3)$, pp. 86-91.

Moores, T. T., and Dhillon, G. 2003. "Do Privacy Seals in E-Commerce Really Work?," Commun. ACM (46:12), pp. 265-271.

National Australia Bank Limited. 2017. "Nab Online Retil Sales Index." from https://business.nab.com.au/wp-content/uploads/2017/11/norsi-sept-2017.pdf

Özpolat, K., and Jank, W. 2015. "Getting the Most out of Third Party Trust Seals: An Empirical Analysis," Decision Support Systems (73), pp. 47-56.

Sarstedt, M., Henseler, J., and Ringle, C. M. 2011. "Multigroup Analysis in Partial Least Squares (Pls) Path Modeling: Alternative Methods and Empirical Results," in Measurement and Research Methods in International Marketing. Emerald Group Publishing Limited, pp. 195-218.

Sia, C. L., Lim, K. H., Leung, K., Lee, M. K., Huang, W. W., and Benbasat, I. 2009. "Web Strategies to Promote Internet Shopping: Is Cultural-Customization Needed?," Mis Quarterly), pp. 491-512. 